\title{
Justicia: Una Mirada Marxista ${ }^{1}$
}

\author{
Justice according to the Marxist
}

\author{
Georgina De León Vargas ${ }^{2}$
}

\section{RESUMEN}

Haciendo referencia a Karl Marx en su libro el capital hablaremos que para MARX la lucha de clases no es un juego es un conflicto. Puesto que en manos del proletariado esta la responsabilidad de consolidar empresas haciendo a los ricos más ricos y a los pobres más pobres: aunque los burgueses pagaran por la labor de un trabajador, la sobreexplotación no era un problema para los burgueses porque de igual forma ellos seguirían siendo ricos y otro pobre ocuparía el lugar del otro por igual o menor salario; Como decía Marx "A primera vista, una mercancía parece ser una cosa trivial, de comprensión inmediata. Su análisis demuestra que es un objeto endemoniado, rico en sutilezas metafísicas $y$ reticencias teológicas" (Karl Marx, El capital)

\section{Palabras claves:}

Karl Marx, justicia, capitalismo, evolución.

\begin{abstract}
Karl Marx referring to in his book Capital Marx talk that the class struggle is not a game is a conflict. Since in the hands of the proletariat is the responsibility of consolidating companies making the rich richer and the poor poorer: while the

\footnotetext{
${ }^{1}$ El presente artículo se deriva de algunos estudios realizados sobre la teoría de Marx en el grupo de investigación de Derecho Público del programa de Derecho de la Corporación Universitaria Rafael Núñez sede Cartagena.

${ }^{2}$ Abogada, Magíster en Derecho Del Trabajo De la Universidad Autónoma de Guerrero México, Docente Coordinador de Investigación del Programa de Derecho de la Corporación Universitaria Rafael Núñez sede Cartagena. Correo: georgina.deleon@curnvirtual.edu.co

ISSN: 2346-2787

Recibido: 11 de abril de 2018

Aprobado: 29 de mayo de 2018.
} 
bourgeois pay for the work of a worker, overexploitation was not a problem for the bourgeoisie because similarly they would follow He is rich and another poor take the place of another for the same or lower wages; As Marx said "At first glance, a commodity seems a trivialhing, understanding immediately. Their analysis shows that is rich in metaphysical subtleties and theological niceties "demonized object. (Karl Marx, Capital)

\section{Keywords:}

Karl Marx, justice, capitalism, evolution.

\section{Introducción}

Este artículo de investigación tiene como propósito analizar el concepto de justicia bajo la óptica de la escuela marxista del derecho. Para ello, se hace necesario establecer tres tipos de análisis partiendo de la teoría social marxista del desarrollo, abarcando el análisis del pasado en el cual Marx desarrolla la temática relacionada con el materialismo histórico o lucha de clases, la critica a los modos de producción del sistema capitalista y planteando una posible aproximación a la transformación de la sociedad por parte del proletariado.

En segundo lugar, será desarrollado lo concerniente al análisis del presente. En dicho punto, Marx plantea una crítica al sistema económico capitalista debido a que éste sirve como medio para oprimir a las clases obrera, fomentando la alienación o enajenación. Y en tercer lugar se tiene el análisis del futuro, en el cual el autor en su obra El manifiesto del partido comunista propone la conquista revolucionaria del poder por parte del proletariado o revolución política del trabajador la cual tendría como fin último establecer el comunismo como sistema económico, político, social y cultural.

Téngase en cuenta que cuando se establezca dicho sistema, no habría división de clases sociales, al igual que oprimidos ni opresores, no habría estado ya que este 
es utilizado como medio de dominación, ni lucha de clases. Con relación al concepto de justicia, en el presente trabajo de investigación se hace necesario abarcar la teoría social marxista del desarrollo y hacer un análisis de la misma debido a que Karl Marx en ningún texto estableció de manera clara y precisa dicho concepto. Siendo así, será analizada y se establecerán los puntos clave o base con relación a la concepción de justicia.

\section{Método.}

La presente artículo se deriva de una investigación de tipo descriptivo, cualitativo y bibliográfico. Teniendo en cuenta la naturaleza de los objetivos que hemos propuesto, será de tipo descriptivo, permitiéndonos establecer cómo ha sido abordado el concepto de justicia por la Escuela Sociológica del Derecho, conoceremos e identificaremos las características de esta última y mediremos estos y otros conceptos relacionados, con el fin de resolver nuestra pregunta problema.

Según la naturaleza de los datos que obtendremos será de tipo cualitativo ya que los datos que adquiriremos no serán cuantificables, no obstante nos brindarán una descripción completa y detallada de nuestro objeto de estudio.

Asimismo, y de acuerdo a la naturaleza de nuestras fuentes de información, será bibliográfica, ya que nuestras unidades de análisis serán documentos escritos por los exponentes de la Sociología del Derecho, en los que localizaremos, clasificaremos y narraremos, sus conceptos y posturas acerca de la justicia.

El diseño metodológico de esta investigación es descriptivo, por ende implica observar y describir el comportamiento de un objeto sin influir sobre él de ninguna manera; servirá para conocer, analizar e interpretar las características, los elementos y las formas en las que ha sido abordado el concepto de justicia en la Escuela Sociológica del Derecho. 
El plan general que hemos adoptado para obtener la respuesta a nuestra pregunta problema, ha consistido en primera instancia en una descripción detallada de nuestro objeto de investigación con el fin de formular una pregunta problema adecuada, lo delimitamos espacial y temporalmente para definir tanto un objetivo general como dos específicos acordes y coherentes. Previo a la definición de los objetivos de la investigación, planteamos cuál sería la importancia que la misma

Tendría en nuestra formación como abogados y posteriormente elaboramos sus referentes teóricos. Especificamos el tipo de investigación que haríamos, las técnicas e instrumentos que usaríamos para la recolección de información, hicimos un cronograma, un cuadro de administración del proyecto y finalmente plasmaremos en un documento escrito los resultados obtenidos, nuestras conclusiones y recomendaciones.

\section{Técnicas e instrumentos de recolección de información}

Las técnicas para recolectar la información que nos permitirán contestar la pregunta problema, teniendo en cuenta el tipo de investigación que desarrollaremos, y las fuentes de información que usaremos serán:

La observación

La investigación bibliográfica o de archivo que consiste en la revisión bibliográfica de un tema para conocer su estado. Los análisis de contenido o documentales nuestras fuentes de información serán tanto primarías como secundarias. Es decir que serán primarias en la medida en la que revisaremos textos y conceptos de los principales exponentes de la Sociología del Derecho, y serán secundarias, pues tendremos en cuenta los análisis y los documentos relacionados con nuestro objeto de estudio que han sido elaborados por autores diferentes a los teóricos de dicha Escuela. 
Las herramientas que nos permitirán registrar la información serán fichas bibliográficas y documentos escritos que elaboraremos a partir de la información que sea recolectada.

\section{Un toque de historia y humanidad frente a la cuestión marxistas.}

Marx no asumía una concepción propia y explícita de justicia, pero haciendo un análisis podemos definir que las críticas al capital eran un llamado de atención evidente a la burguesía. Para la clase baja en la época esta brecha discriminatoria brusca no era solo un problema sino más que eso una guerra a muerte en donde los ganadores eran los burgueses.

Resaltando la frese de marx "más hambre que comida y más comida que hambre" podemos deducir que para entonces había al igual que hoy un desequilibrio social, económico que llevaba a un pueblo vulnerable a la miseria; mas hambre que comida hace referencia a la esclavitud a la que era sometido el proletariado, con pagas paupérrimas por ende hambre y sueño por las extensas horas de trabajo. Más comida que hambre es fácil muy fácil, aquí podemos ver que los capitalistas se hacían más ricos sus empresas más y más poderosas, todo a costillas de la prole, mientras que la prole como son llamados despectivamente los hijos de los más pobres morían de hambre y enfermedades, los capitalistas tenían más comodidades. Marx, Karl (Londres, 25 de julio de 1867) El capital. La jornada laboral, cap.8

Obviamente este gran aporte el cual muchos amantes de los ideales marxistas acogemos con elogio, ha caracterizado positivamente el concepto social y económico de Marx como un ideal que se puede materializar y efectuar en los sistemas políticos actuales, partiendo en que como seres humanos, seres sintientes, seres racionales estamos hechos de la misma materia, por consiguiente 
lo justo sería tener igualdad de oportunidades e iguales derechos que la clase capitalista de la época y no es algo paradójico puesto que sin embargo siendo algunos acaudalados y otros no, estamos compuesto del mismo ingrediente.

La vulneración de derechos y la aniquilación de personas que desean surgir y no hablo de aniquilación física sino de aquella que hace parte del alma y del espíritu humano, es la que vemos en nuestros días, a tal fecha el sistema capital y los colonizadores de hoy no tienen látigos, no tienen grilletes pero si academia, academia que se va perfeccionado cuesta de la huella de la historia, las teorías cambian, la ciencia avanza el hombre junto con ella y el hambre de saber más. Pintamos al diablo con tenedor pero nosotros mismos terminamos siendo satanás o secuaces de él sin darnos cuenta y esto suele pasar cuando sin necesidad de tener el tenedor del diablo podemos aniquilar sueños, con tres simples palabras ¡ERES MI EMPLEADO! Con dos ¡NO PUEDES! Con una ¡INCAPAZ!. Quiero destacar que ningún ser humano es un recurso, somos talento, talento humano capaces de razonar, sentir, construir, desarrollar, innovar, por lo tanto el respeto valor muy importante, debe ir ligado al trato que debemos tener los unos con los otros vengan de donde vengan y hagan lo que hagan.

Haciendo referencia a KARL MARX en su libro EL CAPITAL hablaremos que para MARX la lucha de clases no es un juego es un conflicto. Puesto que en manos del proletariado esta la responsabilidad de consolidar empresas haciendo a los ricos más ricos y a los pobres más pobres: aunque los burgueses pagaran por la labor de un trabajador, la sobreexplotación no era un problema para los burgueses porque de igual forma ellos seguirían siendo ricos y otro pobre ocuparía el lugar del otro por igual o menor salario; Como decía Marx "A primera vista, una mercancía parece ser una cosa trivial, de comprensión inmediata. Su análisis demuestra que es un objeto endemoniado, rico en sutilezas metafísicas y reticencias teológicas". 
Marx, Karl (Londres, 25 de julio de 1867) Tomo 1 El capital. Filosofía y Revolución. Pg., 94 - Aristóteles. Definición de la justicia, Moral a Nicómaco (libro quinto, capítulo primero)

\section{Análisis de la teoría Marxista}

Partiendo de la teoría Marxista del desarrollo, hay que establecer los tres tipos de análisis hecho por Karl Marx en compañía de Friedrich Engels, dentro de los cuales se resalta el Materialismo histórico, la crítica al sistema capitalista y la conquista revolucionaria del poder por parte del proletariado. Posteriormente se los tres tipos de análisis establecidos por Marx los cuales son:

\section{Análisis del Pasado.}

(Materialismo Histórico)

En términos del Dr. Vladimiro Naranjo Mesa el materialismo histórico es "la aplicación de los principios del materialismo dialectico al estudio de la vida social, los fenómenos de la vida de la sociedad, al estudio de ellas y de su historia" NARANJO, M.V (1de enero 1990) Teoría Constitucional e Instituciones Políticas. Edición. Bogotá: Editorial Temis. 200. Pg.582..

El materialismo no es nada más y nada menos que el término acuñado por Karl Marx a: "La lucha de clases", la cual consiste en "el antagonismo y enfrentamiento que se produce entre las clases sociales cuyos intereses son incompatibles y se contradicen entre sí", fue el marxismo e que introdujo este vocablo en las ciencias políticas al considerarlo el motor de la historia. Citando el manifiesto del partido Comunista, Marx establece "La de todas las sociedades que han existido hasta nuestro días es la historia de las luchas de clases"3. Para este pensador fundador del socialismo científico o comunismo, esta lucha de 
clases se da en tres niveles correspondientes a las partes de la estructura social, por ende habrá una lucha económica, ideológica y política. La económica se caracteriza por la resistencia obrera al ser explotada, resistencia que se manifiesta en la defensa de los intereses inmediatos de los trabajadores, sin poner en cuestión el sistema en su naturaleza. La ideológica supone la oposición de distintas concepciones en la sociedad. Por último la política que se manifiesta en el enfrentamiento por la apropiación del poder del estado.

Partiendo del presente análisis, la economía condiciona todo lo demás "(la ideología, la legislación y sistemas políticos), por ello a los marxistas no se les puede dominar ni convencer con argumentos éticos, morales, ni religiosos, jurídicos o políticos" (Marx, K.) (Engels, F.) (1847) Manifiesto del Partido comunista Pg. 19. Estableciendo que la religión es la droga del pueblo "opio",

La cual ha favorecido a los gobiernos y a las políticas, para así oprimir más al proletariado. Citando a Bob Sutcliffe, dentro de la obra Marxismo y Desarrollo, establece que Marx descubrió la ley de desarrollo de la sociedad humana: "El hecho tan sencillo pero oculto bajo la maleza ideológica del hombre de que el hombre necesita en primer lugar comer, beber, tener un techo, vestirse antes de hacer política, arte y religión.

SUTCLIFFE, B (año 1996) Marxismo y Desarrollo. 1aㅡ edición. Madrid: desarrollos y teorías económicas.

Hay que tener en cuenta que la fase económica de desarrollo de un pueblo es la base a partir de la cual se han desarrollado las instituciones políticas, las concepciones artísticas. Ahora bien dentro del análisis del pasado, que se establece el materialismo histórico, Marx hace una crítica al sistema monárquico debido a que servía de ayuda a las reglas establecidas por el clero y la nobleza como tal, pero todo el análisis establecido por este pensador va enlazado con los modos de producción, estableciendo que "la historia es una sucesión de modos de producción injustos"4, debido al sistema económico que genera 
desigualdades entre opresores y oprimidos, generando la llamada explotación del hombre por el hombre. Fundacion Codespa. (Citado el día 21/08/2014).Teoría del desarrollo.

Marx y Engels demostraron la gran importancia de la práctica productiva del hombre e hicieron de ella el principio real de la vida humana. Según ellos "el vínculo que une a los hombres entre sí en clases es el trabajo, la producción. Las clases son los factores reales de la sociedad y la historia de la humanidad es esencialmente la lucha entre unas y otras clases sociales, cuyo fin es la producción y distribución de riquezas", por ello Marx dentro de su tesis con respecto a la teoría del desarrollo establece que la economía juega un rol muy importante dentro de la sociedad. En la época feudal los opresores eran los privilegiados, y los oprimidos los no privilegiados, al igual en que la época antigua, hoy en día se establece ese patrón de dominio por parte del burgo.

\section{Análisis del presente.}

(Análisis y crítica del sistema económico capitalista).

En el presente análisis Marx establece la simplificación entre las luchas de clases por parte delos opresores y oprimido, el principio de la alienación, la plusvalía y el aumento de las desigualdades sociales, llegando así a la transformación revolucionaria de la sociedad donde se establece el triunfo del proletariado.

Teniendo en cuenta la transformación revolucionaria de la sociedad, dentro de los cuales se resalta el cambio hacia un nuevo modo de producción injusto con nuevos opresores y oprimidos, y por lo tanto nueva lucha de clases, se le asigna el nombre de simplificación de los antagonismos de clases, debido a las políticas "(Capitalistas), opresoras al proletariado, los cuales son llamados: oprimidos". Este sistema político capitalista, que anteriormente o aún sigue siendo de estirpe burgués, es producto de principios liberales los cuales forman una estructura oligárquica y utilizan al estado como medio de dominación de las clases sociales. Karl Marx establece dentro del manifiesto del partido comunista 
que "toda sociedad va dividiéndose, cada vez más, en dos campos enemigos, en

dos grandes clases sociales, que se enfrentan directamente: la burguesía (capitalismo) y el proletariado (trabajador)".

(Marx, K.) (Engels, F.) (1847) Manifiesto del Partido comunista Pg.20

Cabe establecer que las políticas del sistema burgués son las mismas. La burguesía ha desempeñado en la historia un papel altamente revolucionario, debido a que donde quiera que haya conquistado el poder, ha destruido las relaciones en la sociedad, ha acabado con las industrias nacionales, debido a que son remplazadas por industrias internaciones; en pocas palabras ha hecho de la dignidad personal un simple valor de cambio, suprimiendo cada vez más el fraccionamiento de los medios de producción, de la propiedad y la población.

Debido a este tipo de políticas capitalistas implantada en gran parte del mundo, ha surgido una problemática la cual es de total importancia, la cual es manifestada por medio del trabajo adicional no remunerado al trabajador desembocado en la Ilamada: "Plusvalía", estableciendo que es la causa fundamental del proceso de acumulación de capital (Enriquecimiento) por parte de la burguesía (Clase dominante). En palabras de Marx "lo que el capitalista paga no es el trabajo-el producto, sino la fuerza de trabajo la aptitud de producir. Al comprar esta fuerza por un día, una semana, etc.... El capitalista obtiene, el derecho de explotarla durante un día, una semana, etc. El tiempo de explotación se divide en dos periodos, Durante uno, la actividad de su fuerza solo produce un equivalente de su precio. Durante el otro, es gratuito, y por consecuencia produce al capitalista un valor por el cual no se paga equivalente alguno que no le cuesta nada. En este caso el sobre-trabajo, de donde se saca la plusvalía, puede denominarse (trabajo no pagado)"

(Marx, K.) (Engels, F.) (1847) Manifiesto del Partido comunista Pg. 162.

Teniendo en cuenta lo anterior cabe establecer que para Marx la plusvalía es un medio utilizado por la clase opresora capitalista o burguesa, con el fin de evadir parte del trabajo del proletariado. Por ende Marx llega a la siguiente conclusión "El 
tipo de la plusvalía es la expresión exacta del grado de explotación de la fuerza de trabajo por el capital o del trabajador por el capitalista" ${ }^{5}$. Con respecto al trabajo asalariado Marx establece "El precio medio del trabajo asalariado es el mínimo del salario, es decir, la suma delos medios de subsistencia indispensables para el obrero, por consiguiente lo que el obrero asalariado se apropia por su actividad es estrictamente lo que necesita para la mera reproducción de su vida. Ahora bien nosotros no queremos de ninguna manera abolir la propiedad privada, sino, suprimir el carácter miserable de esa apropiación, que hace que el obrero no viva".

(Marx, K.) (Engels, F.) (1847) Manifiesto del Partido comunista

Pg.42

Según el pensador no se requiere abolición sino, quitar los vicios en la obtención de la propiedad.

Partiendo de lo anteriormente planteado la plusvalía, aumenta el grado de desigualdad entre las clases sociales, debido a que el trabajo no remunerado por parte del obrero, es faltante para satisfacer las necesidades básicas del proletariado, generando Mayor miseria, enriqueciendo más y más al burgués, y por ultimo creando más diferencias entre las clases sociales. (Mayor pobreza, hambruna, mayor lucha de clases). De ello se desprende la conciencia del proletariado estableciendo que existe una lucha de clases entre opresores y oprimido o (antagonismo de clases). Por ende el fin de la clase marxista es la transformación revolucionaria de la sociedad, estableciendo el triunfo de la revolución proletariado. Karl Marx dentro del presente análisis establece que para llegar al comunismo, en donde la clase obrera triunfaría, había que acabar con el sistema capitalista imperante, pasando por las políticas socialistas y así llegar a la conquista del poder. 


\section{Conclusiones.}

Se realizó un proceso el cual se siguió a través de libros y materiales sobre el tema y se resolvió haciendo un análisis sobre la teoría social Marxista, para así determinar el concepto de justicia y sus alcances como tal.

Por consiguiente se llegó a la conclusión, de que para Karl Marx sí existe un concepto de justicia teniendo en cuenta el sistema económico, social y político que rige. Pero hay que tener en cuenta que la justicia para que exista tiene que ser abolido el sistema capitalista, debido a que este oprime al proletariado. También cabe destacar que como solución a la problemática de la lucha de clase se encuentra la implantación del sistema comunista, dicho sistema estaría por encima de lo que hoy en día se considera como justicia.

Conclusión de la teoría Marxista del desarrollo, Marx estableció la teoría de la siguiente forma:

\begin{tabular}{|l|l|l|}
\hline Tesis & Antítesis & Síntesis \\
\hline Análisis del pasado. & Análisis del Presente & Análisis del Futuro \\
\hline $\begin{array}{l}\text { Lucha de clases- } \\
\text { Materialismo histórico y } \\
\text { dialectico. }\end{array}$ & $\begin{array}{l}\text { Critica al s. capitalista e } \\
\text { implantación del } \\
\text { Socialismo. }\end{array}$ & $\begin{array}{l}\text { Conquista proletariado- } \\
\text { Implantación del } \\
\text { comunismo. }\end{array}$ \\
\hline
\end{tabular}

Karl Marx y Friedrich Engels, desarrollaron la presente teoría, con el fin de contribuir al entendimiento, al análisis crítico histórico y reorientar la teoría del desarrollo hacia la justicia social, con la finalidad de aportar conceptos y categorías para entender el mundo y para la transformación de las relaciones sociales en torno al individuo. 


\section{Referencias.}

Arango, L. A (Biblioteca virtual) Banco de la república. Comunismo.

Aristóteles. Definición de la justicia, Moral a Nicómaco (libro quinto, capítulo primero) Recuperado de:

Carlos Sevilla. (28 de febrero de 2006). Marxismo y la teoría de la justicia. Madrid España: foro interno.

Fundacion Codespa. (Citado el día 21/08/2014).Teoría del desarrollo. Recuperado de: Guiñazú, María Clelia. (2001). Marxismo analítico y justicia: ¿más allá de Rawls?. Buenos Aires: CLACSO, Consejo Latinoamericano de Ciencias Sociales. http://es.slideshare.net/fcodespa/teoria-del-desarrollo-785852. http://www.banrepcultural.org/blaavirtual/ayudadetareas/poli/poli27.htm http://www.filosofia.org/cla/ari/azc01119.htm

Karl Marx. (1847). El Manifiesto del partido comunista. Londres: Longseller.

Karl Marx. (25 de julio 1867). El Capital. Londres: akal.

Marx, Karl. (Recuperado 13 de octubre 2010) Marco teórico. Karl Marx y el marxismo.

Naranjo, M.V (1de enero 1990) Teoría Constitucional e Instituciones Políticas. edición. Bogotá: Editorial Temis.

Sutcliffe, B (año 1996) Marxismo y Desarrollo. 1ª edición. Madrid: desarrollos y teorías económicas. 